\title{
Evaluation and endoscopic management of persistent air leaks
}

\author{
Virgil Secasanu $^{1}$, Sevak Keshishyan ${ }^{2}$, Alberto E. Revelo ${ }^{1}$ \\ ${ }^{1}$ Division of Pulmonary, Critical Care, and Sleep Medicine, Interventional Pulmonology Section, The Ohio State University Wexner Medical Center \\ Columbus, OH, USA; ${ }^{2}$ Division of Pulmonary, Critical Care and Sleep Medicine, Beebe Medical Center, Lewes, DE, USA \\ Contributions: (I) Conception and design: AE Revelo; (II) Administrative support: none; (III) Provision of study materials or patients: None; (IV) \\ Collection and assembly of data: All authors; (V) Data analysis and interpretations: All authors; (VI) Manuscript writing: All authors; (VII) Final \\ approval of manuscript: All authors. \\ Correspondence to: Alberto E. Revelo, MD. Assistant Professor of Medicine, Division of Pulmonary, Critical Care, and Sleep Medicine, Interventional \\ Pulmonology Section, The Ohio State University Wexner Medical Center Columbus, Davis Heart \& Lung Research Institute, 473 West $12^{\text {th }}$ Avenue, \\ Columbus, OH 43210, USA. Email: alberto.revelo@osumc.edu.
}

\begin{abstract}
The endoscopic management of persistent or prolonged air leak (PAL) has gained popularity, not only in post-surgical PAL but also in non-surgical scenarios. The literature that supports an endoscopic approach is restricted to case series, case reports, retrospective and some small prospective studies. Every patient who suffers from PAL secondary to bronchopleural fistula (BPF) or alveolopleural fistula (APF) should always be evaluated to determine surgical repair candidacy. There have been a number of articles that summarize the bronchoscopic modalities for the management of PAL, but none emphasize the initial evaluation with an algorithmic approach or discuss how to follow-up these patients in the immediate posttreatment phase and long-term. Medical causes of PAL are, in our opinion, more difficult to localize and consequently treat compared to surgical causes of air leak. The bronchoscopic management for either surgical or non-surgical BPF's is similar. In this review, we discuss the initial evaluation, management and follow up with an algorithmic approach of PAL as well as review the available endoscopic modalities.
\end{abstract}

Keywords: Persistent air leak (PAL); alveolopleural fistula (APF); pleurocutaneous fistula; bronchopleural fistula (BPF); interventional pulmonology

Received: 28 August 2019; Accepted: 19 November 2019; Published: 10 April 2020.

doi: $10.21037 /$ shc.2019.11.12

View this article at: http://dx.doi.org/10.21037/shc.2019.11.12

\section{Introduction}

Air leakage from the tracheobronchial tree to the pleural space is a pathologic process that can result in pneumothorax, limited ventilation, hypoxia, and death. Immediate recognition of this detrimental process is paramount to patient survival. Usually, air leakage into the pleural space is an iatrogenic phenomenon after interventional procedures such as transbronchial biopsy or lobar resection, although air leak can also occur after unprompted processes such as with spontaneous pneumothorax $(1,2)$. Initial management includes chest drainage of the pleural air with a chest tube to allow for lung reexpansion with resultant cessation of air leakage and removal of the chest tube (3). Air leakage is usually monitored by presence of bubbles in the water seal chamber of a pleural drain, although digital pleural flow meters have also been described (4).

Persistent air leak (PAL) can occur when pleural air leaks for more than 5 days (5). PAL is further characterized based on the location of the air leak: persistent air leakage at the level of the segmental bronchi is termed bronchopleural fistula (BPF), whereas air leakage from the distal tracheobronchial tree is termed alveolopleural fistula (APF). Medical conditions that affect the alveolar and parenchymal structure are more likely to produce APF.

Definitive management of PAL is surgical repair. Both the American College of Chest Physicians and British Thoracic Society recommend early thoracic surgery consultation when a persistent air leak is encountered $(6,7)$. However, and 
especially in APF, patients may be medically complex and with obscure sources of leak that make surgical approaches high risk or impractical. Additional treatment options such as medical pleurodesis or one-way pleural valves may be impractical due to the lack of pleural apposition with brisk air leaks (for successful pleurodesis) or ongoing morbidity and risk of infection (with pleural valves) (8). In recent years, bronchoscopic approaches to PAL have shown promise at resolution of persistent air leaks (8-10). This article seeks to describe the initial evaluation approach to PAL, including localization by traditionally described methods, review of less common but potentially useful diagnostic modalities, and provide a guide on how to monitor air leaks post interventions. We will also discuss the bronchoscopic approaches to its management.

\section{Initial evaluation}

An algorithm for the management of air leaks after pulmonary resection has already been described (11). Medical or non-surgical air leaks are difficult to manage because often a culprit subsegment is not localized with conventional methods; patients may have more than one source of BPF or APF, or may have significant collateral ventilation $(\mathrm{CV})$ as in emphysematous or pulmonary fibrosis lungs. The authors of this review propose an algorithm or guide to initial evaluation and follow up for patients with medical PAL (Figures 1,2). Both the terms APF and BPF will be used interchangeably in this review, as they both lead to the same pathophysiologic process but pose different diagnostic and management challenges and such differences will be pointed out in this manuscript as well.

\section{Clinical presentation}

The presentation of BPF can be variable. BPF has been classified depending on the time of onset as early (1-7 days), intermediate (8-30 days) and late ( $>30$ days) (14). The symptoms are usually cough with purulent sputum, dyspnea, fatigue, fever, weight loss. The acute presentation can be dramatic with sudden onset of dyspnea, hypoxemia, subcutaneous emphysema and hypotension especially in cases with spontaneous pneumothorax with tension physiology. In the post-surgical patient with a chest tube in place, the only presentation may be increased bubbling in the drainage system, which can translated into increased dyspnea or loss of tidal volumes if the patient is on mechanical ventilation. The more common etiology of BPF is post-surgical. It is more common with pneumonectomy rather than lobectomy and after lung volume reduction surgery (LVRS) $(5,15)$. There are many other etiologies of BPFs and APFs (16) and identifying the cause is key to success in management.

\section{Anatomic localization}

\section{Direct visualization}

Direct visualization of a defect is more easily accomplished in cases of BPF after lung resection surgery (5). In these cases, stump dehiscence is evident with bronchoscopic evaluation or via video-assisted thoracoscopic surgery (VATS). If a fistula at the stump is suspected but is too small to be evident during bronchoscopy, interrogation can be accomplished by saline instillation at the stump site; bubbling will indicate the presence of a defect. Direct visualization also allows for targeted deployment of therapies (either endoscopic approaches as discussed below or direct suturing during VATS). However, in contrast to $\mathrm{BPF}$, direct visualization of air leak can be challenging in cases of APF because the distal air leak may be too small and distal to visualize by conventional fiberoptic bronchoscopy.

\section{Balloon occlusion technique}

In 1977, Ratliff and colleagues described a unique approach of anatomic localization of pleural air leak using repetitive balloon occlusion (17). In this technique, a bronchoscope is used to deliver a Fogarty $7 \mathrm{Fr}$ (or similar) catheter, and the balloon is systematically inflated from proximal to distal airways while the air leak in the drainage system is observed. The balloon is inflated, and bubbles in the pleural water seal chamber are monitored for up to 2-3 minutes (9). If occlusion of a suspected segmental bronchus leads to reduction or cessation of bubbles in the water seal chamber (or reduction of flow on a digital system), the pleural air leak must be positioned in the occluded segmental bronchus. This approach can be repeated in successive subsegmental bronchi to better delineate the sublobar location of the air leak. Moreover, once localized, direct bronchoscopic interventions are delivered to the affected airway. An important limitation to this approach is the possibility of CV between lung subsegments, which would make occlusion of one subsegment insufficient to locate the source of air leak. This is a common problem found in severe emphysematous or fibrotic lungs in which the interlobar 


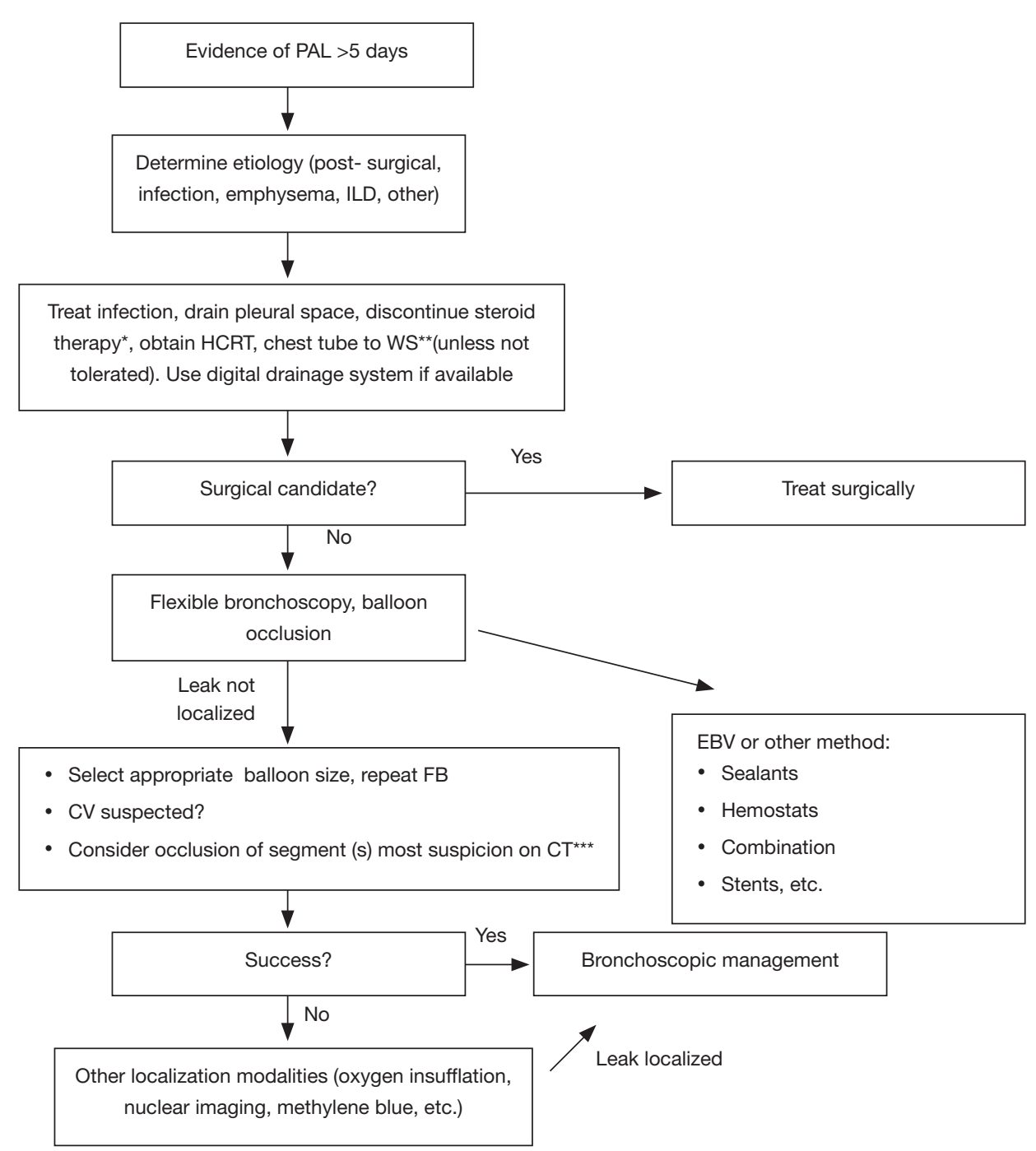

Figure 1 Proposed algorithm for initial evaluation for patients with medical persistent air leak. It is important to perform a thorough physical examination of the patient that includes a careful review of the chest tube site to look for inadvertent kinking or clamping, adequate tidaling, loose connections, and/or malfunctioning pleural drainage system. If a persistent air leak is present ( $>5$ days), one has to determine its etiology as management of the underlying problem can significantly influence success in therapy. Many patients will have an infected pleural space, and antibiotic therapy should be started and broadened as necessary. *, if the patient is on corticosteroid therapy, the dose should be reduced to the lowest possible or discontinued, as this will delay the healing process; ${ }^{* *}$, prospective studies have shown simple water seal is superior to suction on patients with expiratory leaks after pulmonary resection $(12,13)$. The authors of this review believe that ongoing suction will increase the flow through a fistula further delaying the healing process and thus we advocate to keep chest tubes to simple water seal unless otherwise not tolerated by the patient (i.e., enlarging symptomatic pneumothorax or subcutaneous emphysema), and this effect is proportional to the amount of suction applied. Patients should undergo water seal trials periodically. Every patient should be evaluated by thoracic surgery for fistula repair if the patient is deemed a candidate. Otherwise, flexible bronchoscopy should be performed to localize and treat at one procedure; ${ }^{* * *}$, alternative methods for localization as described in the body of this review should be sought if traditional balloon occlusion fails. If collateral ventilation is suspected, a careful review of the CT images with information gathered at first bronchoscopy can help decide which segment (s) or lobe should be occluded. Many times the leak is not completely stopped after the first intervention, however, most of the times is significantly reduced and that should be regarded as a step towards success. PAL, persistent air leak; ILD, interstitial lung disease; HCRT, high resolution computed tomography; WS, water seal; CV, collateral ventilation; FB, fiberoptic bronchoscopy; CT, computed tomography; EBV, endobronchial valves. 


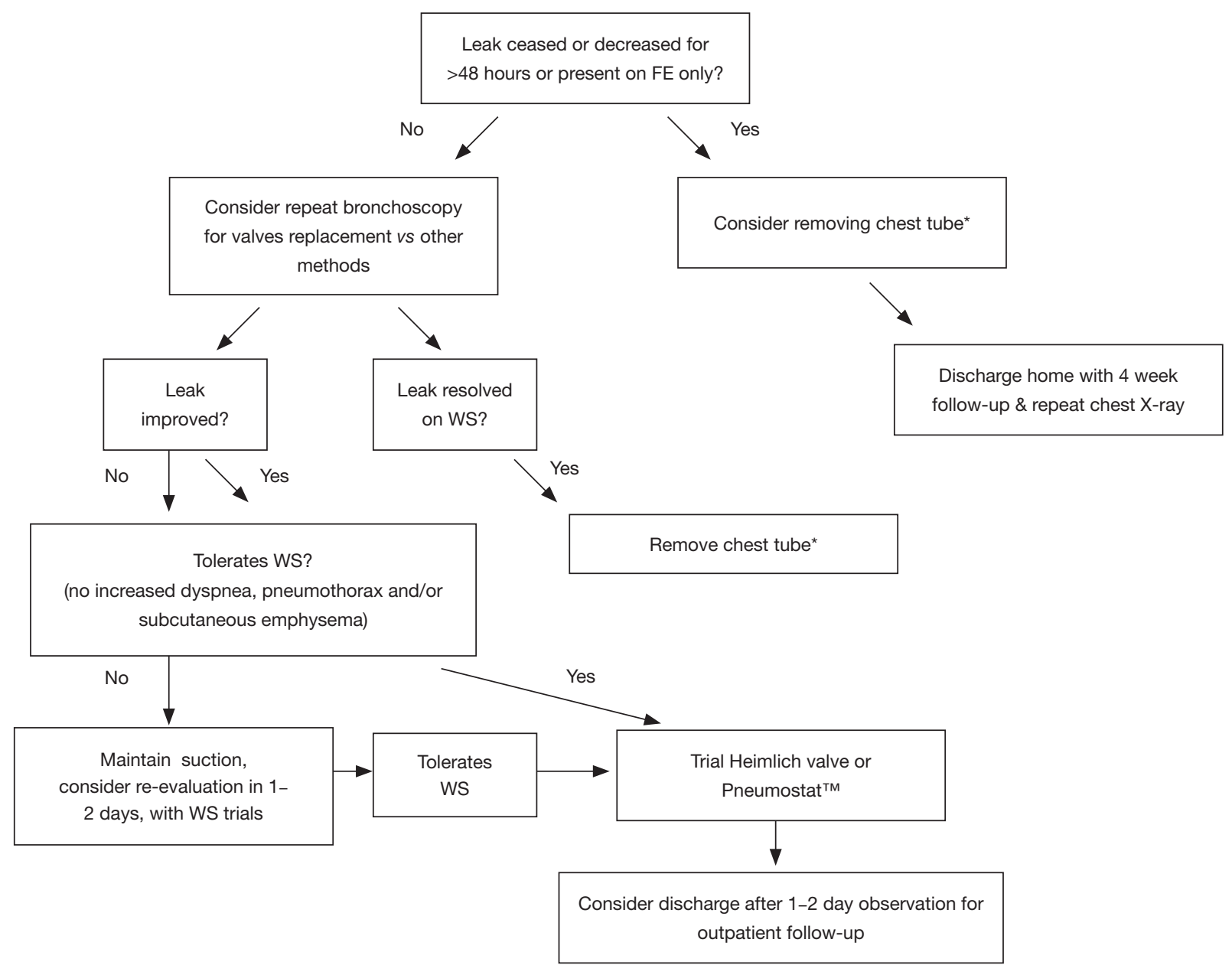

Figure 2 Proposed algorithm for follow-up evaluation for patients with medical persistent air leak. The patient should be observed for at least 48 hrs after any endobronchial therapy. Daily chest X-ray should be obtained. The chest tube and pleural drainage system should be checked and leak quantified, if still present. *, if there is absence of air leak, the chest tube should be removed after a clamping trial. If the leak is unchanged, worsened or pneumothorax is not resolved, consider repeat bronchoscopy for other interventions that may include valve revision/replacement or other endobronchial therapies. If the leak is improved, water seal trial should be re-attempted. If the patient tolerates water seal without increasing dyspnea, enlarging pneumothorax and/or subcutaneous emphysema occurrence, a portable drainage device should be placed (i.e., Heimlich or Pneumostat ${ }^{\mathrm{TM}}$ ) and patient observed for $24-48$ hrs before discharge. At this point, an outpatient plan with short-term follow up should be established. If the leak did not improve with a repeat intervention and the patient is unable to tolerate water seal, the chest tube should remain to suction but attempts to transition to water seal should be made every $1-2$ days, with the goal of at least discharge with a portable device, should the patient tolerate. Adequate nutritional support is key in the management. Evaluation for possible oxygen needs, especially on ambulation should also be determined before discharging the patient. FE, forced exhalation; WS, water seal.

fissures may not be intact (8). Some authors advocate that inability to pinpoint the leak with balloon occlusion method precludes any endoscopic intervention (18); however endoscopic intervention may be the only option for such patients, and we suggest trying alternative methods of APF localization as described below.

\section{Computer tomography (CT) imaging}

CT imaging can also aid in anatomic localization. In a 2002 retrospective trial, Ricci and colleagues describe 33 patients with BPF and in which 18/33 (55\%) chest CT was useful in localizing the BPF or its probable cause such 
as bullae or abscess (19). An additional imaging option is use of a multidetector CT (MDCT). In MDCT, a 2-dimensional array is used rather than the linear detector array of conventional CT; the increased detector density allows the machine to acquire images faster, thereby limiting motion artifacts and improving image quality $(20,21)$. MDCT images can allow for improved resolution of gas accumulation, abscess formation, or direct fistula localization to aid in treatment planning. One limitation to CT imaging is the need for supine positioning during image acquisition, which may be intolerable for patients with brisk air leaks or septic pleural processes. Nevertheless, high resolution computed tomography (HRCT) can be very helpful in localizing APF. The clinician should invest sufficient time reviewing these images before bronchoscopy and for potential anatomic localization. CT thin-cut images can provide a plethora of information and sometimes directly pinpoint the pleural defect and be able to track it down to a particular subsegment.

\section{Virtual bronchoscopy}

Post-processing of MDCT data can allow for formation of 3-dimensional reconstructions to simulate endobronchial views of the major tracheobronchial tree segments, known as virtual bronchography (VB) $(22,23)$. Data on the use of VB is limited mainly to case reports; in 2010 Sarkar and colleagues reported 4 cases of $\mathrm{BPF}$ in which $\mathrm{VB}$ images aided in localization of the fistula and treatment planning (20). VB is limited in visualizing smaller air leaks such as APF. Moreover, VB can have a high false-negative rate if the fistula is occluded with debris or mucus during the image acquisition process.

\section{Nuclear imaging}

Nuclear imaging modalities utilize inhalation of a radioisotope-tagged substance, most commonly labeled with Technetium-99m $\left({ }^{99 m} \mathrm{Tc}\right)$, to generate images that show likely location of air leaks. All studies are limited to case series. In 1994 Nielsen and colleagues presented a series of 6 patients where ventilation scintigraphy was used to locate possible air leaks; patients inhaled the radioactive substance and serial two-dimensional images were obtained to locate extrapulmonary gas leaks (24). Further work has shown this technique to be a viable approach to fistula localization $(25,26)$.

Incorporation of the radioisotope with concurrent CT imaging is regarded as SPECT/CT, whereby a CT is used to generate the post-inhalational images (27-29). One major limitation to both ventilation scintigraphy and SPECT/CT is reduced accuracy in parenchymal lung diseases such as chronic obstructive lung disease; in such diseases, turbulent parenchymal gas flow can lead to aerosol deposition in the distal parenchyma and generate a false-positive result.

\section{Metbylene blue instillation}

Instillation of methylene blue to the pleural space has been shown to be effective in localizing small pleural leaks in case reports. Both retrograde and anterograde methylene blue instillation has been reported. In 2013, van Zeller and colleagues described the technique whereby, under sedation, one clinician injects intrapleural methylene blue and another clinician simultaneously inspects the bronchi with a bronchoscope for appearance of intrabronchial methylene blue (30). The technique has also been replicated by Sakata and colleagues (31). In 2014, Jin et al. reported the successful localization of the culprit segments or subsegments in all 27 patients enrolled by instilling methylene blue via the working channel of the bronchoscope. The average volume of methylene blue used to localize the responsible airway (s) was $42 \mathrm{~mL}$. Three out-of- 27 patients had more than one subsegment involved. All patients were treated with fibrin glue, however not all responded to the elected therapy. There were no reported complications from methylene blue instillation (32).

\section{Oxygen insufflation}

In 2013, Vial and colleagues presented an ingenious protocol for localization of low-flow fistulas that are common of APFs (33). In such low-flow fistulas, patients are sedated under general anesthesia with a pleural drain in place. A bronchoscope is advanced with low-flow oxygen (typically $2-4 \mathrm{~L} / \mathrm{min}$ ) attached to the suction valve port of the bronchoscope. With the bronchoscope wedged in selected bronchial segments, oxygen is delivered selectively via the suction valve ("insufflated") to the bronchus. The water seal on the pleural drain catheter is monitored during active 2-second insufflation bursts. Presence of fistula will result in bubble forming on the water seal. The risk of barotrauma is presumably low, as insufflating oxygen at $2 \mathrm{~L} / \mathrm{min}$ flow during two-second bursts would generate a volume of gas less than $70 \mathrm{~mL}$. The pressure generated with this maneuver was found to be minimal as reported by the 
authors.

\section{Intrabronchial capnography measurement}

In 2010, Moody and colleagues presented a case report whereby an intrabronchial capnography catheter was used to measure changes in carbon dioxide (34). The pleural drain was disconnected from the water seal and exposed to the atmosphere. The intrabronchial capnographic catheter was advanced to suspected subsegmental bronchi. A lack of carbon dioxide returns on the catheter output indicated an opening to the atmosphere and likely location of the fistula. Although ingenious in concept, this approach necessitates loss of pleural negative pressure, which may be harmful if the lung collapses. Larger studies are needed to verify the sensitivity and specificity of this approach.

\section{Chartis device}

The Chartis Pulmonary Assessment Catheter (Pulmonx Corporation, Redwood City, CA, USA) is a catheter equipped with a pressure and flow transducer that can be bronchoscopically placed in selected bronchi. The catheter was initially developed to determine $\mathrm{CV}$ for planning of bronchoscopic lung volume reduction (BLVR) (35). A balloon on the distal end of the catheter seals the catheter to the bronchial walls to measure airflow and pressure distal to the balloon. Experience is growing throughout the world with this technology, showing it can help determine dynamic airway collapse distal to the catheter $(36,37)$. A recent report by Tian and colleagues demonstrated the use of Chartis to locate lung segments with persistent air leak (38). Although not directly shown to aid in pleural fistula localization, one can postulate the Chartis device would show pressure and flow changes indicating possible $\mathrm{CV}$ and that more than one subsegment may require intervention.

\section{Monitoring air leaks}

Pleural drains are the mainstay of monitoring persistent air leaks to prevent intrathoracic gas accumulation, pneumothorax, and formation of tension physiology. The most commonly described approach to monitoring ongoing air leaks is assessing for bubble formation under a water seal. These bubbles are the result of inspired atmospheric gas being transmitted to the alveoli and leaking into the pleural space. This approach of monitoring bubbles has been the gold standard of monitoring air leaks and used in many prior studies $(8,17,33)$. One limitation to this approach has been the subjectivity with bubble formation and quantification of leakage. Digital read-out pleural chest drainage technologies have sought to be more objective and improve inter-clinician assessment of air leaks.

The Thopaz system (Medela AG, Baar, Switzerland) is one such digital pleural drainage system consisting of a portable suction unit and a digital readout of the pleural flow, which can include air leakage. In 2009, Rathinam and colleagues surveyed $\mathrm{n}=15$ nursing staff caring for a total of 120 patients with the Thopaz chest drainage system placed after VATS surgery. Nursing staff reported "very good" (13/15) with overall device assessment (39). A recent 2014 pilot, observational study by Tunnicliffe and colleagues showed the Thopaz system safe and effective in management of $n=13$ patient with pneumothorax (40). Additional advantages of The Thopaz system is potential for improved patient mobilization, and the ability to display real time data allowing for a continuous flow monitoring. The manufacturer recommends removing a chest tube when the leak is less than $50 \mathrm{~mL} / \mathrm{min}$ without major variation or 'spikes' for the preceding six hours. The use of the Thopaz system versus the traditional drainage system to monitor and quantify air leaks really depends on institutional availability of either equipment. The authors of this manuscript recommend the use of a digital reader over traditional when available, as it provides more objective data potentially facilitating decision-making on the timing for chest tube removal.

\section{Bronchoscopic management modalities for BPF and APF}

Surgical management of a BPF is the traditional gold standard approach for this difficult-to-treat condition. The mortality for post-pneumonectomy empyema is considerably high ranging from $23-50 \%$ with or without a fistula, and the mortality associated with surgery is about $10 \%$ (41). Surgical re-evaluation for the diagnosis, localization, and surgical repair of a fistula by directly suturing the stump or using flaps in those with good surgical candidacy should always be the first step in management (42). Pleural management modalities could also be implemented by using talc as a primary sclerosant or different other substances like blood patch, silver nitrate, and antibiotics (minocycline, doxycycline, tetracycline) $(43,44)$. However, pleural sclerosis is not always feasible if the lung is not fully expandable. 
Due to the nature of this morbid condition, many times patients are often not suitable candidates for surgery, either due to ongoing infection like pneumonia, empyema, malnutrition and/or poor lung function as in severe obstructive or restrictive lung impairments. In recent decades, advances in the field of interventional pulmonology have allowed for novel opportunities for non-surgical, bronchoscopic management in so-called poor surgical candidates or those who failed the surgical approach. It is important to mention that the management of PAL should have a multi-disciplinary team approach of surgeons, pulmonologists, radiologists, nursing and other support staff and that careful patient selection for a specific diagnostic and treatment modality is the key for success. As mentioned earlier in this article, understanding the underlying etiology, which lead to PAL, is the most important deciding factor to select the right treatment modality.

As an example, for patients with primary spontaneous pneumothorax without serious medical comorbidities surgical approach would be preferable. In contrast to this, patient with secondary spontaneous pneumothorax with underlying severe emphysema surgical option would be risky and with a high recurrent rate. The same is true for different bronchoscopic options for PAL. Patient with interstitial lung disease complicated by pneumothorax and PAL may not tolerate permanent closure of segmental or subsegmental bronchus and for these patients with limited lung reserve endobronchial valves (EBV) would be preferable.

The list of bronchoscopic treatment options for PAL is long and includes: EBV, airway stents, endobronchial spigots, hemostatic sealants, tissue adhesives (glues), bronchoscopic submucosal injections of tissue expanders and sclerosants, blood patch, thermal therapies (argon plasma coagulation), coils and septal defect closure devices.

\section{$E B V$}

There are two types of endobronchial one-way valves available: The Zephyr ${ }^{\circledR}$ (Pulmonx Corp, Redwood City, CA, USA) and the Spiration ${ }^{\circledR}$ Valve System (Olympus Respiratory, Redmond, WA, USA). Both are currently FDA approved for the treatment of advanced emphysema, and both have previously been used for PAL management. Of these two devices, the Spiration ${ }^{\circledR}$ product is approved by the US Food and Drug Administration (FDA) and available exclusively under the Humanitarian Device Exemption Program for postoperative PAL complicating lung resectional surgery (45).

The Spiration ${ }^{\circledR}$ valve comes in four different sizes: 5,6 , 7 , and $9 \mathrm{~mm}$. It has an umbrella-shape polymer supported by a nickel-titanium (Nitinol) frame with anchors to hold it in place. The Zephyr ${ }^{\circledR}$ valve comes in two sizes: 4.0 and 4.0 LP (Low Profile) and $5.0 \mathrm{~mm}$. The LP was designed for use in shorter airway segments. The 4.0 valve is used in airways ranging from $4-7 \mathrm{~mm}$ diameter, and the 5.0 valve in 5.5-8.5 mm diameter airways. The Zephyr ${ }^{\circledR}$ valve contains a one-way silicone duckbill valve with a Nitinol, selfexpanding retainer covered by a silicone membrane. Both valve systems come with their respective kits that contain deployment catheters. Removal of either type of valve is easily accomplished with the use of a flexible forceps. Both valves have now been FDA approved for the treatment of emphysema. The Spiration ${ }^{\circledR}$ Valve System should not be used in patients who have diffuse homogeneous emphysema $(46,47)$.

The first EBV in humans was placed by Snell in 2005 using the Zephyr ${ }^{\circledR}$ valve for a broncho-cutaneous fistula (48). By far, EBV seem to be the most commonly used devices for PAL in the US in recent decades. This is possibly related to their ready availability, relative simplicity of placement, and ease of removal. There are no multicenter, randomized controlled trials demonstrating efficacy of EVB for the management of PAL but here we mention the largest publications related to their use. There are also several case series and interesting case reports on EVB use for PAL in many different underlying lung condition (49-52). These studies are predominantly retrospective cohort studies and few prospective ones with small number of patients enrolled. There is a prospective study done by Firlinger et al. using both types of valves in 13 out of 19 patients with success rate of $77 \%$ with mean time of chest tube removal of 7.6 days (53). Another prospective study done by Dooms et al. in 2014 using Spiration ${ }^{\circledR}$ valve system in 9 patients with procedural success rate of $67 \%$ and median time of chest tube removal of 4 days (54). Both prospective studies reported no immediate complication related with valves including deaths, hemoptysis, post obstructive pneumonia and et. In a retrospective study published by Travaline et al. in 2009, 40 patients with PAL treated with Zephyr ${ }^{\circledR} \mathrm{EBV}$ with procedural success rate of $93 \%$ with mean time of pleural drain removal of 21 days (median 7.5 days with IQR of 3 to 29 days) and complication rate of $15 \%$ (55). One of the largest multicenter but retrospective studies published by Gilbert et al. in 2016 from eight centers by using 
Spiration ${ }^{\circledR}$ valve system on 75 patients out of 112 evaluated. Procedural success rate was $56 \%$ with median time of chest tube removal after EVB placement of 4 days and 3\% complication rate (56). In 2018, Fiorelli et al. published another retrospective multicenter trial using Zephyr ${ }^{\circledR}$ EBV system in 67 patients with complete resolution of air leaks in $88 \%$ of patients and reduction of air leak in $9 \%$ of patients. Mean chest tube removal days were $7.3 \pm 2.7$ and complication rate reported to be $1 \%$ (57). The VAST trial (Valves against Standard Therapy) is another notable study initiated in 2015 by Spiration Inc. as multicenter (20 locations), randomized, and controlled study to compare EBV versus standard chest tube management of PAL with primary outcome of cessation of air leak and target enrollment of 200 subject. Unfortunately the study was suspended due to enrollment issues, with a pending interim analysis yet to be released at the time of this review (ClinicalTrials.gov Identifier: NCT02382614).

\section{Endobronchial spigots}

Watanabe first reported the usage of silicone made endobronchial plug for treatment of BPF in 1991 in Japan (58). Endobronchial spigots are most widely used for PAL in Asian countries and especially in Japan. In Japan, they are officially recognized for management of PAL but not yet FDA approved in US. Endobronchial Watanabe Spigots (EWS) coated with barium sulfate for better radiographic visibility. They come in small, medium and large sizes 5, 6 and $7 \mathrm{~mm}$ respectively. Its surface has small studs, to prevent migration. As with EBV, most of the data on spigots come from case series and mainly from Japan. One of the recent case series reported by Morikawa et al. in 2016 with usage curette to install EWS in 11 consecutive patients with persistent pneumothorax. They were able to remove chest tubes from 8 patients with $72.7 \%$ success rate (59). Two earlier case series from Japan presented in Table 1.

It is worth mentioning that since its introduction, spigots have gained popularity and additional indications. In addition to using for PAL data is available on spigot use for hemoptysis and BPF with empyema (62). Spigots as well as EBV are removable and the temporary use makes them attractive for short-term management of PAL, BPF, and hemoptysis.

\section{Tissue adhesives and hemostatic agents}

These substances are commonly used in surgical practice for tissue repair and as hemostatic agents. Most widely used tissue adhesive is cyanoacrylate (Tissue seal, Histoacryl ${ }^{\circledR}$, Ann Arbor, MI, USA). One of the early reports using cyanoacrylate compound to close artificially created BPF in dogs was described by Menard et al. in 1988 (63). Cepeda et al. described the adequate technique of using glue in the airway for the closure of a $3 \mathrm{~mm}$, post lobectomy bronchopleural fistula. They used a $5 \mathrm{Fr}$ angioplasty catheter for injection and while keeping sufficient distance between tip of the catheter and bronchoscope tip. Both the injection angiocath and the bronchoscope was withdrawn en-bloc to avoid the sealant to enter the working channel of scope (64). Chawla et al. treated 9 patients with BPF by injecting cyanoacrylate compound with overall success rate of $89 \%$. They recommended a safety distance between the tip of the bronchoscope and the tip injection catheter to be $4 \mathrm{~cm}$ (65). In 1994 report, which was updated on 2000, Scappaticci et al. reported $70 \%$ success rate of using cyanoacrylate in 20 post—surgical BPFs (66).

Hemostatic agents like fibrin glue $\left(\right.$ Tissee $\left.^{\circledR}\right)$, cellulose, hydrogel $\left(\right.$ Coseal $\left.^{\circledR}\right)$, and absorbable gelatin sponge (Gelfoam ${ }^{\circledR}$ prepared from purified porcine skin gelatin) are also widely used in surgical practice. Hollaus et al. described using fibrin and combination of fibrin and calf bone (in BPFs larger than $3 \mathrm{~mm}$ ) via rigid bronchoscopy in 29 postsurgical patients with successful closure of fistula in 16 patients (67). Coseal ${ }^{\circledR}$ application reported in relatively large case series performed by Mehta et al. in 22 medical patients with $\mathrm{BPFs}$ using flexible bronchoscope with a success rate of $86 \%(68)$.

\section{Septal defect closure devices and endobronchial stents}

Septal defect closure devices like Amplatzer occluders (Amplatzer ${ }^{\circledR}$ Septal Occluder, Amplatzer ${ }^{\circledR}$ Duct Occluder II and Amplatzer ${ }^{\circledR}$ Vascular Plugs) are commonly used in the cardiology field. Their usefulness in pulmonology has proved successful in some cases of BPF. They are made of a Nitinol mesh and polyester, which allows epithelialization with time. In 2014 Fruchter et al. published article about long-term efficacy of BPF closure using Amplatzer devices (Amplatzer duct occlude and Amplatzer Vascular Plugs). A total of 31 patient were treated with Amplatzer devices, 24 of which were post-surgical BPFs (14 post pneumonectomy and 10 post lobectomy and segmentectomy). Immediate success rate reported to be $96 \%$ with short-term mortality (less than 30 days) $13 \%$ from unrelated causes. Average follow up period was 17.6 months. During this follow up 
Table 1 Comparison of two case series using EWS for management of PAL

\begin{tabular}{llll}
\hline First author & Number of patients & Elimination of PAL (\%) & Reduction of PAL (\%) \\
\hline Watanabe (60) & 60 & 39.7 & 37.9 \\
Kaneda (61) & 21 & 29 & 57 \\
\hline
\end{tabular}

EWS, Endobronchial Watanabe Spigots; PAL, prolonged air leak.

Table 2 Metallic stents for treatment of BPF, two case series

\begin{tabular}{lllll}
\hline First author & Type of intervention & Predominant fistula etiology/size & Number of patients & Success rate (\%) \\
\hline Cao et al. (72) & Under fluoroscopic guidance & Surgical/3.5-25 mm & 9 & 100 \\
Dutau et al. (73) & Rigid bronchoscopy & Surgical/6-12 mm & 7 & 100 \\
\hline
\end{tabular}

BPF, bronchopleural fistula.

time, there was no need for repositioning or removal and there was not a case of device migration. In the long term follow up period no patient died due to BPF recurrence (69). This report and similar reports from other authors suggest that Amplatzer devices can be safe and effective modality for large BPF management in experienced hands (70).

Endobronchial stents are mainly used for large BPFs most common after surgical with resultan stump dehiscence. In the current literature, there are reports of custom made metallic stent usage for fistula treatment adjusted to specific fistula size and shape (71). Two relatively large series reported by Cao et al. and Dutau et al. are seen in Table 2 .

\section{Miscellaneous modalities}

There are several additional modalities, devices, and substances that were invented during decades of research and clinical trials to address the problem of persistent air leak and intractable pneumothorax. The modalities combined in this group are broad and include submucosal injections of tissue expanders and sclerosing agents like silver nitrate, tetracycline, pure ethanol, ethanolamine, polidocanol, as well as the use thermal therapies and endobronchial coils (74-79). Unfortunately, as with most of the literature with endoscopic management of PAL, the data these miscellaneous approaches are limited to case reports or series at the best. The choice of modality to treat BPF or APF not only depends on the underlying lung pathology but also on the expertise and availability of resources in specific institutions.

\section{Patient follow-up}

\section{Immediate post-procedure care}

Once the air leak has been addressed with an endoscopic method, the ongoing follow-up and monitoring is key to patient recovery. Often the leak would decrease or cease at the conclusion of bronchoscopy; however, sometimes the leak persists, albeit at a smaller scale or only with forceful exhalation. The patient should be monitored for the following 24-48 hrs because significant changes can occur: air leak cessation, worsening, or no change. The entire chest tube and pleural drainage system should be carefully inspected as with initial evaluation. The patient should be questioned about changing symptoms and examined for subcutaneous emphysema. The air leak should be quantified daily and documented in the patient's chart. A chest plain film image should be obtained daily to evaluate for pneumothorax resolution or progression. A repeat $\mathrm{CT}$ is rarely needed at this point in the care. Once the air leak has resolved or the patient tolerates water seal trial with subsequent clamping, the chest tube should then be removed in the usual fashion.

\section{Long-term care}

Outpatient follow-up is a critical portion of care of patients who have been treated with any endoscopic interventions. If a patient received EBV, they should be followed regularly to monitor for the risks associated with $\mathrm{EBV}$, including migration, infection, and persistent cough (45). There is no 
set period for removal of EBV; however the United States Food and Drug Administration recommends valve removal six weeks after placement for persistent air leaks and sooner if complications arise (80). If the patient is treated with other treatment modalities like fibrin sealants, airway stents, spigots or other occlusion devices, a scheduled followup and bronchoscopy is recommended to evaluate for migration, granulation tissue formation, stent clean up, and possible device removal.

A final consideration is extrathoracic manifestation of PAL. Patients who experience PALs secondary to bronchopleural or APF may experience significant weight loss, deconditioning, and protein-caloric malnutrition, especially if PAL was the consequence of a pleuro-pulmonary infectious process. Referral to pulmonary rehabilitation and nutritional support should be considered (41).

\section{Conclusions}

Persistent air leaks, and particularly APFs, are challenging clinical cases due to the relatively small size of the leak. Moreover, the primary diagnoses that make such area leaks more probable (including chronic obstructive pulmonary disease, empyema, and pulmonary fibrosis) also make medical management more challenging and frequently preclude definitive surgical interventions. Localization of the air leak with a minimally invasive approach is of paramount importance. We describe here several techniques to localize the air leak; of these, direct visualization (if possible) and balloon occlusion are most supported in the literature, albeit with case report studies. Potential new modalities for localization of the air leak include retrograde methylene blue instillation, SPECT/ CT imaging, and endobronchial oxygen insufflation. When the leak is anatomically located, and surgical intervention is deemed too risky, bronchoscopic interventions such as EBV and intrabronchial occlusive substances can be offered for treatment.

\section{Acknowledgments}

Funding: None.

\section{Footnote}

Provenance and Peer Review: This article was commissioned by the Guest Editors (Douglas Kyle Hogarth and Jonathan S. Kurman) for the series "Interventional Pulmonology and
Advanced Bronchoscopy" published in Shangbai Chest. The article has undergone external peer review.

Conflicts of Interest: All authors have completed the ICMJE uniform disclosure form (available at http://dx.doi. org/10.21037/shc.2019.11.12). The series "Interventional Pulmonology and Advanced Bronchoscopy" was commissioned by the editorial office without any funding or sponsorship. The authors have no other conflicts of interest to declare.

Ethical Statement: The authors are accountable for all aspects of the work in ensuring that questions related to the accuracy or integrity of any part of the work are appropriately investigated and resolved.

Open Access Statement: This is an Open Access article distributed in accordance with the Creative Commons Attribution-NonCommercial-NoDerivs 4.0 International License (CC BY-NC-ND 4.0), which permits the noncommercial replication and distribution of the article with the strict proviso that no changes or edits are made and the original work is properly cited (including links to both the formal publication through the relevant DOI and the license). See: https://creativecommons.org/licenses/by-nc-nd/4.0/.

\section{References}

1. Singhal S, Ferraris VA, Bridges CR, et al. Management of alveolar air leaks after pulmonary resection. Ann Thorac Surg 2010;89:1327-35.

2. Wood DE, Cerfolio RJ, Gonzalez X, et al. Bronchoscopic management of prolonged air leak. Clin Chest Med 2010;31:127-33, Table of Contents.

3. Chee CB, Abisheganaden J, Yeo JK, et al. Persistent airleak in spontaneous pneumothorax--clinical course and outcome. Respir Med 1998;92:757-61.

4. Cerfolio RJ, Varela G, Brunelli A. Digital and smart chest drainage systems to monitor air leaks: the birth of a new era? Thorac Surg Clin 2010;20:413-20.

5. DeCamp MM, Blackstone EH, Naunheim KS, et al. Patient and surgical factors influencing air leak after lung volume reduction surgery: lessons learned from the National Emphysema Treatment Trial. Ann Thorac Surg 2006;82:197-206; discussion 206-7.

6. Baumann MH, Strange C, Heffner JE, et al. Management of spontaneous pneumothorax: an American College of Chest Physicians Delphi consensus statement. Chest 
2001;119:590-602.

7. MacDuff A, Arnold A, Harvey J, et al. Management of spontaneous pneumothorax: British Thoracic Society Pleural Disease Guideline 2010. Thorax 2010;65 Suppl 2:ii18-31.

8. Revelo A, Keshishyan S, Epelbaum O, et al. Diagnostic and therapeutic challenges in managing persistent air leaks. J Thorac Dis 2018;10:522-8.

9. Lazarus DR, Casal RF. Persistent air leaks: a review with an emphasis on bronchoscopic management. J Thorac Dis 2017;9:4660-70.

10. Keshishyan S, Revelo AE, Epelbaum O. Bronchoscopic management of prolonged air leak. J Thorac Dis 2017;9:S1034-46.

11. Cerfolio RJ, Tummala RP, Holman WL, et al. A prospective algorithm for the management of air leaks after pulmonary resection. Ann Thorac Surg 1998;66:1726-31.

12. Cerfolio RJ, Bass C, Katholi CR. Prospective randomized trial compares suction versus water seal for air leaks. Ann Thorac Surg 2001;71:1613-7.

13. Marshall MB, Deeb ME, Bleier JI, et al. Suction vs water seal after pulmonary resection: a randomized prospective study. Chest 2002;121:831-5.

14. Varoli F, Roviaro G, Grignani F, et al. Endoscopic treatment of bronchopleural fistulas. Ann Thorac Surg 1998;65:807-9.

15. Darling GE, Abdurahman A, Yi QL, et al. Risk of a right pneumonectomy: role of bronchopleural fistula. Ann Thorac Surg 2005;79:433-7.

16. Sato M, Saito Y, Fujimura S, et al. [Study of postoperative bronchopleural fistulas--analysis of factors related to bronchopleural fistulas]. Nihon Kyobu Geka Gakkai Zasshi 1989;37:498-503.

17. Ratliff JL, Hill JD, Tucker H, et al. Endobronchial control of bronchopleural fistulae. Chest 1977;71:98-9.

18. Slade M. Management of pneumothorax and prolonged air leak. Semin Respir Crit Care Med 2014;35:706-14.

19. Ricci ZJ, Haramati LB, Rosenbaum AT, et al. Role of computed tomography in guiding the management of peripheral bronchopleural fistula. J Thorac Imaging 2002;17:214-8.

20. Sarkar P, Patel N, Chusid J, et al. The role of computed tomography bronchography in the management of bronchopleural fistulas. J Thorac Imaging 2010;25:W10-3.

21. Nair A, Godoy MC, Holden EL, et al. Multidetector $\mathrm{CT}$ and postprocessing in planning and assisting in minimally invasive bronchoscopic airway interventions. Radiographics 2012;32:E201-32.
22. Polverosi R, Vigo M, Baron S, et al. Evaluation of tracheobronchial lesions with spiral CT: comparison between virtual endoscopy and bronchoscopy. Radiol Med 2001;102:313-9.

23. De Wever W, Vandecaveye V, Lanciotti S, et al. Multidetector CT-generated virtual bronchoscopy: an illustrated review of the potential clinical indications. Eur Respir J 2004;23:776-82.

24. Nielsen KR, Blake LM, Mark JB, et al. Localization of bronchopleural fistula using ventilation scintigraphy. J Nucl Med 1994;35:867-9.

25. Mark JB, McDougall IR. Diagnosis and localization of bronchopulmonary air leaks using ventilation scintigraphy. Chest 1997;111:286-9.

26. Raja S, Rice TW, Neumann DR, et al. Scintigraphic detection of post-pneumonectomy bronchopleural fistulae. Eur J Nucl Med 1999;26:215-9.

27. Ceulemans G, De Meirleir L, Keyaerts M, et al. Air leaks localized with lung ventilation SPECT. Clin Nucl Med 2012;37:1182-3.

28. Duncker D, Beutel G, Konig T, et al. Localizing the air vents: functional imaging-guided diagnosis in extensive multilocal subcutaneous emphysema. Circ Cardiovasc Imaging 2013;6:1115-6.

29. Derlin T, Salamon J, Laqmani A. Value of (99m)TcTechnegas SPECT/CT for Localization of Alveolarpleural Fistulas. Nucl Med Mol Imaging 2016;50:164-5.

30. van Zeller M, Bastos P, Fernandes G, et al. Clinical challenges of persistent pulmonary air-leaks--case report. Rev Port Pneumol 2014;20:162-6.

31. Sakata KK, Nasim F, Schiavo DN, et al. Methylene Blue for Bronchopleural Fistula Localization. J Bronchology Interv Pulmonol 2018;25:63-6.

32. Jin P, Ge H, Peng L, et al. Clinical investigation of detecting the bronchi responsible for pulmonary air leakage by injecting methylene blue saline in 27 cases with intractable pneumothorax and bronchial fistula. Zhonghua Jie He He Hu Xi Za Zhi 2014;37:831-4.

33. Vial MR, Lan C, Cornwell L, et al. Endobronchial oxygen insufflation: a novel technique for localization of occult bronchopleural fistulas. Ann Am Thorac Soc 2013;10:157-9.

34. Moody GN, Zeno BR. Localization and treatment of bronchopleural fistula through capnography. J Bronchology Interv Pulmonol 2010;17:261-3.

35. Shah PL, Herth FJ. Current status of bronchoscopic lung volume reduction with endobronchial valves. Thorax 2014;69:280-6. 
36. Gesierich W, Samitas K, Behr J. Determining collateral ventilation during bronchoscopy: unanswered questions. Thorax 2014;69:289-90.

37. Shah PL, Herth FJ. Dynamic expiratory airway collapse and evaluation of collateral ventilation with Chartis. Thorax 2014;69:290-1.

38. Tian Q, Qi F, An Y, et al. Using the Chartis system to selectively target a lung segment with a persistent air leak. Eur Respir J 2013;41:1461-3.

39. Rathinam S, Bradley A, Cantlin T, et al. Thopaz Portable Suction Systems in Thoracic Surgery: an end user assessment and feedback in a tertiary unit. J Cardiothorac Surg 2011;6:59.

40. Tunnicliffe G, Draper A. A pilot study of a digital drainage system in pneumothorax. BMJ Open Respir Res 2014;1:e000033.

41. Wain JC. Management of late postpneumonectomy empyema and bronchopleural fistula. Chest Surg Clin N Am 1996;6:529-41.

42. Puskas JD, Mathisen DJ, Grillo HC, et al. Treatment strategies for bronchopleural fistula. J Thorac Cardiovasc Surg 1995;109:989-95; discussion 995-6.

43. Droghetti A, Schiavini A, Muriana P, et al. Autologous blood patch in persistent air leaks after pulmonary resection. J Thorac Cardiovasc Surg 2006;132:556-9.

44. Cobanoglu U, Melek M, Edirne Y. Autologous blood pleurodesis: A good choice in patients with persistent air leak. Ann Thorac Med 2009;4:182-6.

45. Spiration. Spiration Valve Instructions for Use. Available online: www.spiration.com/IFU. Accessed August 10, 2019.

46. FDA. Spiration Valve System. Available online: www.fda. gov/medical-devices/recently-approved-devices/spirationvalver-system-p180007. Accessed August 26, 2019.

47. FDA. Zephyrr Endobronchial Valve System. Available online: www.fda.gov/medical-devices/recently-approveddevices/zephyrr-endobronchial-valve-system-p180002. Accessed August 26, 2019.

48. Snell GI, Holsworth L, Fowler S, et al. Occlusion of a broncho-cutaneous fistula with endobronchial one-way valves. Ann Thorac Surg 2005;80:1930-2.

49. Cusumano G, Fiorelli A, Bellofiore S, et al. Endoscopic one-way endobronchial valves in the treatment of persistent air leak with empyema: A Case Series. Eur Respir J 2018 52: PA4688.

50. Bader S, Faul C, Raab S, et al. Successful long-term treatment of persistent pulmonary air leak in pneumocystis jirovecii pneumonia by unidirectional endobronchial valves. Respir Med Case Rep 2018;25:170-3.

51. Ghiani A, Hansen M, Tsitouras K, et al. Endobronchial One-Way Valve Therapy Facilitates Weaning from Extracorporeal Membrane Oxygenation in a Patient with ARDS and Persistent Air Leak. Case Rep Crit Care 2018;2018:9736217.

52. Romero-Legro IH, Fonseca Fuentes X. First Case of Endobronchial Valves for Persistent Air Leak After Mycetoma Resection in a Bilateral Lung Transplant Recipient. Am J Respir Crit Care Med 2019;199:A3140.

53. Firlinger I, Stubenberger E, Müller MR, et al. Endoscopic one-way valve implantation in patients with prolonged air leak and the use of digital air leak monitoring. Ann Thorac Surg 2013;95:1243-9.

54. Dooms CA, Decaluwe H, Yserbyt J, et al. Bronchial valve treatment for pulmonary air leak after anatomical lung resection for cancer. Eur Respir J 2014;43:1142-8.

55. Travaline JM, McKenna Jr RJ, De Giacomo T, et al. Treatment of persistent pulmonary air leaks using endobronchial valves. Chest 2009;136:355-60.

56. Gilbert CR, Casal RF, Lee HJ, et al. Use of one-way intrabronchial valves in air leak management after tube thoracostomy drainage. Ann Thorac Surg 2016;101:1891-6.

57. Fiorelli A, D'Andrilli A, Cascone R, et al. Unidirectional endobronchial valves for management of persistent air-leaks: results of a multicenter study. J Thorac Dis 2018;10:6158.

58. Watanabe Y, Hiraki S, Araki M, et al. Bronchial embolization using dental impression material in a case of pyelo-bronchial fistula with Candida fungemia. J Jpn Soc Bronchol 1991;13:607-10.

59. Morikawa S, Okamura T, Minezawa T, et al. A simple method of bronchial occlusion with silicone spigots (Endobronchial Watanabe Spigot; EWS®) using a curette. Ther Adv Respir Dis 2016;10:518-24.

60. Watanabe Y, Matsuo K, Tamaoki A, et al. Bronchial occlusion with endobronchial Watanabe spigot. J Bronchology Interv Pulmonol 2003;10:264-7.

61. Kaneda H, Minami K, Nakano T, et al. Efficacy and long-term clinical outcome of bronchial occlusion with endobronchial Watanabe spigots for persistent air leaks. Respir Investig 2015;53:30-6.

62. Kho SS, Chan SK, Yong MC, et al. Endobronchial embolization for life-threatening hemoptysis with Endobronchial Watanabe Spigot. BMC Res Notes 2017;10:304.

63. Menard JW, Prejean CA, Tucker WY. Endoscopic closure of bronchopleural fistulas using a tissue adhesive. Am J 
Surg 1988;155:415-6.

64. Cepeda S, Pajares V, Trujillo-Reyes JC, et al. A New Cyanoacrylate Used as Bronchial Sealant in the Endoscopic Treatment of Bronchopleural Fistula. Arch Bronconeumol 2017;53:168-9.

65. Chawla RK, Madan A, Bhardwaj P, et al. Bronchoscopic management of bronchopleural fistula with intrabronchial instillation of glue (N-butyl cyanoacrylate). Lung India 2012;29:11.

66. Scappaticci E, Ardissone F, Ruffini E, et al. Postoperative bronchoplenral fistula: Endoscopic closure in 12 patients. Ann Thorac Surg 1994;57:119-22.

67. Hollaus PH, Lax F, Janakiev D, et al. Endoscopic treatment of postoperative bronchopleural fistula: experience with 45 cases. Ann Thorac Surg 1998;66:923-7.

68. Mehta HJ, Malhotra P, Begnaud A, et al. Treatment of alveolar-pleural fistula with endobronchial application of synthetic hydrogel. Chest 2015;147:695-9.

69. Fruchter O, El Raouf BA, Abdel-Rahman N, et al. Efficacy of bronchoscopic closure of a bronchopleural fistula with amplatzer devices: long-term follow-up. Respiration 2014;87:227-33.

70. Klotz LV, Gesierich W, Schott-Hildebrand S, et al. Endobronchial closure of bronchopleural fistula using Amplatzer device. J Thorac Dis 2015;7:1478.

71. Chae EY, Shin JH, Song H-Y, et al. Bronchopleural fistula treated with a silicone-covered bronchial occlusion stent. Ann Thorac Surg 2010;89:293-6.

72. Cao M, Zhu Q, Wang W, et al. Clinical application of fully covered self-expandable metal stents in the treatment of bronchial fistula. Thorac Cardiovasc Surg 2016;64:533-9.

doi: $10.21037 /$ shc.2019.11.12

Cite this article as: Secasanu V, Keshishyan S, Revelo AE. Evaluation and endoscopic management of persistent air leaks. Shanghai Chest 2020;4:19.
73. Dutau H, Breen DP, Gomez C, et al. The integrated place of tracheobronchial stents in the multidisciplinary management of large post-pneumonectomy fistulas: our experience using a novel customised conical selfexpandable metallic stent. Eur J Cardiothorac Surg 2011;39:185-9.

74. García-Polo C, León-Jiménez A, López-Campos JL, et al. Endoscopic sealing of bronchopleural fistulas with submucosal injection of a tissue expander: a novel technique. Can Respir J 2010;17:e23-4.

75. Watanabe S, Watanabe T, Urayama H. Endobronchial occlusion method of bronchopleural fistula with metallic coils and glue. Thorac Cardiovasc Surg 2003;51:106-8.

76. Lim AL, Kim CH, Hwang YI, et al. Bronchoscopic ethanolamine injection therapy in patients with persistent air leak from chest tube drainage. Tuberc Respir Dis (Seoul) 2012;72:441-7.

77. Kiriyama M, Fujii Y, Yamakawa Y, et al. Endobronchial neodymium: yttrium-aluminum garnet laser for noninvasive closure of small proximal bronchopleural fistula after lung resection. Ann Thorac Surg 2002;73:945-8.

78. Kanno R, Suzuki H, Fujiu K, et al. Endoscopic closure of bronchopleural fistula after pneumonectomy by submucosal injection of polidocanol. Jpn J Thorac Cardiovasc Surg 2002;50:30-3.

79. Martin WR, Siefkin AD, Allen R. Closure of a bronchopleural fistula with bronchoscopic instillation of tetracycline. Chest 1991;99:1040-2.

80. Gillespie CT, Sterman DH, Cerfolio RJ, et al. Endobronchial valve treatment for prolonged air leaks of the lung: a case series. Ann Thorac Surg 2011;91:270-3. 